\title{
Quilombos e quilombolas: entre o conceito e a politização semântica
}

\section{Quilombos and quilombolas: between the concept and the politization semantic}

Benedito Souza Filho - Antropólogo, professor do Departamento de Sociologia e Antropologia e do Programa de Pós-graduação em Ciências Sociais da UFMA. E-mail: beso45@uol.com.br

\section{Resumo}

A mobilização política dos quilombolas, com vistas à regularização de seus territórios após a promulgação da Constituição de 1988, possibilitou o trabalho acadêmico de revisão conceitual das noções de quilombo e quilombola gestadas no contexto da escravidão. $\mathrm{O}$ resultado desse trabalho intelectual foi apropriado por agentes sociais situados em diferentes lugares institucionais. $\mathrm{O}$ artigo busca analisar o contexto e os elementos que permitiram a formulação dos novos conceitos de quilombo e quilombola e a sua utilização por diferentes agentes, como uma espécie de politização semântica.

\begin{abstract}
The political mobilization of the quilombolas in order to regularize their territories after the promulgation of the 1988 Constitution allowed the academic work of conceptual revision of the notions of quilombo and quilombola gestated in the context of slavery. The result of this intellectual work has been appropriated by social actors situated in different institutional places. The article analyzes the context and the factors that enabled the formulation of new concepts of quilombo and quilombola and its use by different actors as a kind of politization semantics.
\end{abstract}

\section{Palavras-chave}

\section{Keywords}

Território. Quilombo. Mediadores. Politização semântica. 


\section{INTRODUÇÃO}

O cenário acadêmico e político em torno da chamada "questão quilombola" pós-Constituição de 1988 possibilitou tanto a mobilização de grupos, com vistas à regularização de seus territórios, quanto o trabalho intelectual relativo à revisão conceitual dos entendimentos de quilombo e quilombola herdados da escravidão.

A movimentação política desses sujeitos de direito na interlocução com o Estado para fins de titulação de seus territórios permitiu a visibilidade de distintas situações sociológicas que contribuíram para a ampliação das discussões conceituais em torno do tema. O resultado do trabalho reflexivo acabou sendo apropriado por atores sociais situados em distintos lugares institucionais. A utilização das categorias quilombo e quilombola por esses agentes sociais, na nova conjuntura, acabou dando lugar a diferentes sentidos e significados. O presente artigo procura refletir justamente sobre isso: entender os elementos postos em jogo, relacionados com os novos entendimentos de quilombo e quilombola e a sua politização semântica.

Na programação do III Congresso Brasileiro de Pesquisadores Negros, realizado em São Luís, no Maranhão, em 2004, houve uma Mesa Redonda intitulada "Sociedades Quilombolas Contemporâneas". Chamou-me a atenção o título e fiquei imaginando o que teria justificado sua escolha. Talvez o estabelecimento do título estivesse associado à visibilidade do tema naquele momento; ou ao desejo dos organizadores de darem uma conotação sociológica e política ao mesmo. Pode-se supor, ainda, que desejassem expressar a ideia de que, em função da visibilidade das lutas travadas por inúmeras comunidades quilombolas espalhadas pelo país, devêssemos designá-las de sociedades quilombolas e não mais de comunidades.

É inegável que a luta de muitas das chamadas comunidades remanescentes de quilombos, amparadas no dispositivo constitucional - o Artigo 68 dos Atos das Disposições Constitucionais Transitórias - tem contribuído para a visibilidade do tema e dos problemas por elas enfrentados. A indicação de tal título talvez estivesse associada ao movimento de valorização não só da luta e visibilidade do problema, mas também de uma ação coletiva ancorada em uma identidade acionada politicamente.

Ainda que o termo sociedade, em função de seu uso corriqueiro, pareça ser facilmente entendido, poupando grandes explicações, devemos ter em conta que a "economia na denotação e na conotação pode tanto estimular o pensamento como restringi-lo. Entretanto, não é suficiente inventar ou importar palavras novas: precisamos examinar de perto nosso instrumental intelectual" (WOLF, 
2003, p. 307). Em função disso, e tomando como referência o título da Mesa Redonda do Congresso antes mencionado, colocaria as seguintes questões: o que seriam as sociedades quilombolas contemporâneas? É possível usar tal designativo para o caso brasileiro e no plural? ou, para acompanhar uma tendência política e acadêmica, seria mais pertinente falar simplesmente comunidades quilombolas on comunidades remanescentes de quilombos? Creio que uma primeira preocupação seria a de saber se é adequado falar nestes termos. A expressão sociedades quilombolas contemporâneas assume a feição de uma hipérbole e, como tal, deve ser relativizada.

Ao falar da necessidade de relativizar a ideia de sociedades quilombolas, poderia ser colocado o problema dos limites conceituais e das possibilidades de suas formulações. Já que a realidade pode ser interpretada segundo diferentes perspectivas, poder-se-ia argumentar, com base em Wolf (2003), que:

[...] sendo a realidade o que se disser que ela é, qualquer um pode 'jogar', usando quaisquer instrumentos que escolher. Mas se o projeto é de explicação e não de entretenimento, então a avaliação sobre a adequação de nossos conceitos continua a ser uma questão séria” (WOLF, 2003, p. 307).

Anthony Giddens (1991, p. 21) ressalta que "o conceito de 'sociedade' ocupa uma posição focal no discurso sociológico", ainda que possa estar sujeito a ambiguidades ou sugerir distintas interpretações teóricas ${ }^{1}$. Domingues (1999) afirma que "Quando se fala em sociedade, quer-se de fato referir a sistemas de interação social nos quais o estado-nação delimita fortemente as fronteiras em que essas interações se realizam" (DOMINGUES, 1999, p.157).

Em decorrência desses limites, penso que a expressão sociedades quilombolas abriga certa limitação, já que não formaria um universo à parte do Estado brasileiro, mas parte integrante do mesmo. O seu uso como emblema se enquadraria mais a um movimento de semântica política, do que propriamente a uma existência social independente.

Existiria muito mais um movimento de aglutinação de forças, que pode ser pensado em termos de uma ação coletiva de mobilização política, no qual os mediadores assumem um destacado protagonismo, mais do que propriamente a constituição de sociedades quilombolas.

Essa mobilização se processaria no sentido de promover articulações entre agentes sociais referidos a realidades específicas. Tais agentes estariam historicamente vinculados a distintas situações sociológicas que, por critérios

\footnotetext{
Não é meu interesse proceder aqui a uma discussão pormenorizada do conceito de sociedade. Uma leitura estimulante pode ser a de Eric Wolf (2003), em "Inventando a Sociedade", em que realiza reflexões sugestivas acerca desse conceito.
} 
acadêmicos ou políticos, puderam ser caracterizadas como ocupações especiais, comunidades negras rurais ou terras de preto. No novo cenário político, essas distintas categorias sociológicas passaram a ser abarcadas pela designação de comunidades remanescentes de quilombo.

As distintas realidades, localizadas para além das denominações operadas no campo político, militante ou intelectual pretendem se consolidar, guardandose as particularidades sociais e históricas que definem tais situações sociológicas, como unidades politicamente organizadas em termos formais e associativos.

A articulação dessas unidades acaba forçando, por meio de pautas reivindicatórias, a abertura de canais de interlocução, principalmente com o Estado, a fim de que sejam atendidas as demandas coletivas oriundas das distintas situações sociológicas espalhadas pelo país.

Colocar em relevo tais questões significa chamar a atenção para uma certa naturalização e politização de conceitos por parte de militantes, instituições de diferentes tipos e o próprio Estado. Chama-nos a atenção a diversidade de usos e de significados que as noções de quilombo, quilombolas, remanescentes de quilombos têm adquirido. Creio que a utilização da expressão sociedades quilombolas acaba servindo como exemplo disso. A prática militante acabou realizando uma naturalização dessas noções.

A emergência dessa naturalização está vinculada à produção social de significados ou mesmo a uma intencionalidade. Os usos, sentidos e necessidades estão relacionados com unidades discursivas (FOUCAULT, 1997) referidas a sujeitos e lugares específicos de enunciação que, num primeiro momento, merecem ser mapeados para que se compreendam os fins ou objetivos que justificam a enunciação, assim como a posição daquele que enuncia.

Além desse aspecto, a construção de significados relacionados às noções de quilombo, quilombolas ou termos correlatos tem implicações políticas, ideológicas e conceituais, pois todas elas definem interesses que precisam ser identificados, já que se referem também a um campo de disputa associado ao seu uso ou à sua caracterização.

As minhas argumentações serão orientadas nessa direção. Procurarei sublinhar, a partir das fontes de enunciação, alguns aspectos de natureza conceitual, política e ideológica e, ao mesmo tempo, identificar os campos de interesse referidos aos lugares dessas enunciações. Portanto, não centrarei as minhas indagações a partir de uma situação etnográfica específica, que possa ser identificada ou pensada como comunidade remanescente de quilombo, mas sim aos diferentes campos antes referidos, que tomam essas realidades localizadas como referência. 


\section{MARCOS CONCEITUAIS, POLÍTICOS E IDEOLÓGICOS}

O mundo social está permeado de idéias, noções e conceitos derivados de reflexões acadêmicas que o senso comum acabou incorporando ao seu discurso cotidiano. O próprio entendimento de sociedade, ainda que complexo, pode ser apontado como um deles. Em torno dessa noção parece existir um consenso de que, ao ser proferido, o seu significado seja imediatamente decodificado e compreendido. Por seus usos corriqueiros, muitos desses conceitos acabaram sendo de certo modo naturalizados, sem que isso representasse um problema grave.

Embora isso ocorra com certa frequência, existem situações que, referidas a segmentos ou a necessidades específicas, acabam demandando uma especialização na sua caracterização, passando a ser manejadas por agentes sociais específicos ou especialistas em determinados circuitos ou circunstâncias.

Os problemas enfrentados pelos grupos sociais que partilham um pertencimento étnico, bem como a necessidade de caracterizá-los como remanescentes de quilombos, podem ser apresentados como exemplo da exigência dessa caracterização. Em decorrência disso, o entendimento de quilombo e seus termos derivados, acaba sendo incorporado ao jargão dos especialistas, empenhados na tarefa de refletir sobre os mesmos e assegurar-lhes validez conceitual, assim como ao dos agentes sociais ou instituições diretamente a eles referidos ou que deles se utilizam.

Ainda que o debate em torno do conceito de quilombo e seus derivados não seja uma exclusividade dos antropólogos, já que historiadores, arqueólogos, advogados, entre outros, têm também se dedicado ao seu estudo, a fonte de sustentação das suas argumentações tem como base situações históricas e sociológicas específicas. É delas que são extraídos os elementos que lhes permitem elaborar suas reflexões.

Estabelecendo contato com antropólogos ou funcionando como colaboradores na busca ou fornecimento de informações, agentes sociais ou integrantes de instâncias de mediação que lhes prestam apoio acabam absorvendo muitos desses conceitos formulados pelos antropólogos, como os de quilombo ou comunidade remanescente de quilombo.

A relação estreita desses agentes e mediadores com os especialistas, e a adoção de termos próprios dos pesquisadores, acaba gerando um tipo de capital que, manejado politicamente, funciona como fator de diferenciação, à medida que empresta prestígio àqueles que se valem dessa apropriação, permitindo, 
igualmente, que se transformem em interlocutores privilegiados na relação com as estruturas oficiais ou mesmo com instituições de apoio ou de financiamento.

No trânsito de uma esfera à outra, ou seja, da dimensão analítica e conceitual àquela da militância política ou da ação institucional, as formulações dos antropólogos podem sofrer alterações. Esse complexo movimento, orientado em vias distintas e interconectadas, caracteriza-se no que Giddens (1974) denominou de dupla hermenêutica.

Segundo Geertz (1989, p. 15), “o homem é um animal amarrado a teias de significados". De acordo com tal perspectiva, a vida social se configuraria como uma enorme teia de significados e essa hermenêutica de que fala Giddens seria o mecanismo que os agentes sociais, assim como os pesquisadores acionariam para compreender os símbolos E os significados que não só eles, mas outros elaboram.

Apropriando-nos dessa formulação de Giddens, poderíamos ressaltar que na construção dos significados e entendimentos de quilombo e seus derivados, ocorre a geração de uma múltipla hermenêutica, referida a campos específicos, sejam eles de natureza acadêmica, política ou ideológica. Assim, na construção dessa múltipla possibilidade, estariam em jogo as perspectivas e interesses dos agentes sociais vinculados às chamadas comunidades remanescentes de quilombos, assim como os dos intelectuais, dos mediadores, das instituições de financiamento e apoio, como também do próprio Estado.

Com relação ao campo intelectual (BOURDIEU, 1983), existem antropólogos e antropólogas que têm se empenhado em refletir sobre os novos entendimentos de quilombo e quilombola, ainda que nem sempre convergindo em suas argumentações (ALMEIDA, 2002; BRASILEIRO; SAMPAIO, 2002; LEITE, 1999; O’DWYER, 1995; GUSMÃO, 1995; PAULA ANDRADE, 2003; ARRUTI, 2006, SOUZA FILHO; PAULA ANDRADE, 2007; FIGUEIREDO, 2011), cujas análises, além de contribuir para o aprofundamento da discussão conceitual, têm reforçando a ação dos movimentos sociais empenhados nas lutas pela garantia de direitos territoriais às chamadas comunidades remanescentes de quilombos.

Os avanços nesse campo da discussão e aprofundamento conceituais, segundo O’Dwyer (2002) têm

[...] orientado a elaboração de relatórios de identificação, os chamados laudos antropológicos, no contexto da aplicação dos direitos constitucionais às comunidades negras rurais consideradas remanescentes de quilombos, de acordo com o preceito constitucional (O’DWYER, 2002, p. 15). 
Além dessa importância reflexiva, relacionada a uma aplicabilidade legal no campo intelectual, também se verifica a consolidação de certo nível de especialização temática, levando à organização de grupos de trabalho sobre quilombos ou outras atividades que ajudam a consolidar esse campo. Assim, em torno das discussões relativas ao entendimento de quilombos, remanescentes de quilombos ou termos correlatos, que auxiliam na configuração desse campo, verifica-se o que Bourdieu (1992, p. 100) denominou de "instituição de uma autoridade".

Aqui, os antropólogos acabaram assumindo um lugar de destaque porque foram eles que tomaram para si a tarefa de gestar, de nomear e, de certo modo, impor o conceito. Como argumenta Pierre Bourdieu (1996, p.111), "o ato de categorização é um ato de magia social que dá existência à coisa nomeada, estabelece fronteira, delimita limites. A eficácia do discurso de categorização, nomeação é maior quanto maior for a autoridade que o enuncia”.

Em relação aos quilombos como tema e problema, e às questões deles derivadas, percebe-se que o campo intelectual é uma seara que não está imune às disputas não só relacionadas com o debate acadêmico, mas também com a concentração do conhecimento, o que acaba contribuindo para a geração de espaços de legitimação e de poder referentes à própria produção acadêmica, como também a diferentes níveis de interlocução, seja com instituições de diferentes tipos ou mesmo com o Estado.

Os novos entendimentos de quilombo, quilombola ou remanescentes de quilombo, por possuírem no seu campo de significados elementos de natureza política, histórica e ideológica, requerem um esforço analítico mais rigoroso para que o seu sentido, no presente, não se confunda com os velhos entendimentos ou assuma um significado social extemporâneo, desvinculado das situações atuais às quais os novos significados de quilombo e quilombola se dirigem ${ }^{2}$. Ainda segundo O’Dwyer (2002):

[...] A identidade histórica de 'remanescente de quilombo' emerge como resposta atual diante de uma situação de conflito e confronto com grupos sociais e econômicos e agências governamentais que passam a implementar novas formas de controle político e administrativo sobre o território que ocupam (O’DWYER, 1995, p. 121).

Em decorrência dessa situação de conflito ou ameaça, a identidade de remanescente de quilombo acaba funcionando como uma identidade de resistência,

Com relação aos distintos significados de quilombo, leia-se Almeida (1996) "Quilombos: sematologia face a novas identidades". 
[...] Criada por atores que se encontram em posições/condições desvalorizadas e/ou estigmatizadas pela lógica da dominação, construindo, assim, trincheiras de resistência e sobrevivência com base em princípios diferentes dos que permeiam as instituições da sociedade, ou mesmo opostos a estes últimos (CASTELLS, 2001, p. 24).

$\mathrm{Na}$ luta pelo reconhecimento legal de segmentos sociais como remanescentes de quilombos, prevalece a ideia de uma sobrevivência no presente, de estruturas sociais pretéritas. Como bem sublinhado por O’Dwyer (2002),

[...] acontece que o texto constitucional não evoca apenas uma 'identidade histórica' que pode ser assumida e acionada na forma da lei. Segundo o texto, é preciso, sobretudo, que esses sujeitos históricos presumíveis existam no presente e tenham como condição básica o fato de ocupar uma terra que, por direito, deverá ser em seu nome titulada (O’DWYER, 2002, p. 14).

Com relação a esse aspecto, e diante da necessidade de ver atendidas as demandas dos agentes sociais, existe um problema a ser enfrentado: o de refletir sobre a ideia de uma continuidade histórica, que não seja entendida como sinonímia de sobrevivência (referida às formas de organização de situações sociológicas específicas), a partir de uma descontinuidade conceitual (relacionada com as formulações analíticas que caracterizariam tais situações sociais ao longo do tempo).

Aqui, cabe o cuidado de não reificar a ideia de continuidade histórica como fator de legitimação das chamadas comunidades remanescentes de quilombo. É certo que determinados elementos da organização social dessas comunidades sofrem alterações ao longo do tempo. Nem por isso, podemos afirmar que os fatores estruturantes das mesmas se perdem nessa dinâmica. O trabalho etnográfico, nesse caso, cumpre um papel fundamental. Os levantamentos genealógicos, arquivísticos e os relatos orais referentes à história e à organização social contribuem para a identificação dessa continuidade, ao mesmo tempo em que permitem identificar os elementos que caracterizam tais comunidades como grupos étnicos em termos organizacionais (BARTH, 1976, p. 15).

Um aspecto a reter é que quilombo, quilombolas, remanescentes de quilombos, nos termos que têm sido empregadas atualmente, como mecanismos para assegurar direitos territoriais a segmentos sociais específicos, são categorias datadas. $\mathrm{Na}$ nova perspectiva conceitual, representa um esforço de ruptura com antigos significados do passado escravo, que não servem para explicar, no presente, as diferentes situações sociológicas espalhadas pelo país.

A formulação do novo conceito de quilombo é tributária de um contexto social e de lutas políticas que demandam a sua emergência. Paralelamente à 
necessidade de tratar da questão da continuidade histórica de grupos sociais que apresentam organização social ancorada em bases étnicas, como forma de solucionar ou mitigar enfrentamentos violentos ou evitar os efeitos daninhos de políticas oficiais de expropriação justificadas como de utilidade pública, diferentes conceitos ou perspectivas analíticas foram sendo produzidos ao longo do tempo, ora para caracterizar as especificidades das diferentes situações sociológicas, ora para reuni-las a partir das lutas políticas.

O que ocorre atualmente é que, diante dos graves problemas enfrentados e das lutas travadas no sentido de garantir a permanência desses grupos em seus territórios, o conceito de comunidade remanescente de quilombo, na nova perspectiva analítica, tem sido acionado como forma de aglutinar diferentes situações sociológicas, que outrora eram conceituadas e vistas separadamente, já que eram revestidas de especificidades em termos organizacionais e históricos. Nessa nova tendência reflexiva, as identidades individuais e coletivas como pretos ou caboclos, por exemplo, que regulam pertencimentos e princípios de inclusão e exclusão, são articuladas no sentido de definir unidades étnicas que o entendimento corrente de remanescente de quilombo sintetiza.

Nesse movimento reflexivo, ocorre uma espécie de aglutinação identitária que a engenharia conceitual ajuda a operar. Nesse sentido, vale ressaltar que na ação político-mobilizatória e de diálogo com o Estado, tal perspectiva conceitual tem a sua importância justamente no fato de que, ao mesmo tempo em que contribui para assegurar territórios a esses segmentos sociais caracterizados como remanescentes de quilombo, preserva, no plano das realidades localizadas, as especificidades sociais e históricas.

Essas mesmas identidades de autoatribuição, que de certo modo ficam subsumidas na designação genérica de remanescentes de quilombos, eram as mesmas que emprestavam sentido à constituição das chamadas terras de preto, terras de santo, terras da pobreza (ALMEIDA, 2006; FERNANDES, 1994; SOUZA FILHO, 2008), por exemplo. É por essa razão que ressalto a questão da descontinuidade conceitual, já que as formulações de categorias analíticas se vinculam ora a preocupações eminentemente acadêmicas, ora a preocupações políticas, associadas à gravidade de problemas e à urgência de sua superação.

As revisões conceituais e lutas políticas que servem, por um lado, para ressemantizar antigas definições de quilombos e, por outro, assegurar direitos territoriais, ainda que importantes, segundo a forma como são apropriadas por mediadores ou instituições de diferentes tipos, acabam gerando, diríamos assim, efeitos colaterais. Tais efeitos seriam o de transformar artificialmente os entendimentos de quilombos e quilombolas em emblemas ou categorias endógenas, 
referidas a grupos específicos. Cabe aqui ressaltar que tal tendência não é operada no campo intelectual, mas por outros agentes ou instituições fora dele, naquele movimento de apropriação dos conceitos formulados pelos intelectuais, já sublinhado anteriormente.

Seria o caso de tentar transformá-los, por meio de uma prática militante, em categorias nativas, a partir de sua utilização como novos emblemas identitários e genéricos. Nesse sentido, a preservação das especificidades sociais e históricas, que na perspectiva analítica não são perdidas de vista, acabam sendo colocadas em segundo plano, em virtude da importância política que os entendimentos de quilombo ou remanescente de quilombo passam a assumir para os mediadores políticos; ou em decorrência dos interesses de distintas instituições, sejam elas oficiais, de apoio (nacionais e internacionais) ou de outra natureza.

A ação militante dos mediadores ou os interesses de instituições de apoio ou de financiamento acaba impondo, como um selo, esse modelo superficial de caracterização, politizando e naturalizando uma noção, como se fosse autoexplicativa e indiferenciada.

A força para a imposição do emblema classificatório não recairia nos agentes sociais dessas situações sociológicas, mas principalmente nas instâncias de mediação. A ação político-mobilizatória dos mediadores estaria engendrando, por meio de uma prática militante, a construção de um léxico específico a ser manejado pelos agentes sociais das realidades localizadas, agora não mais referidas como terras de preto, terras de santo ou terras de santíssimo (SOUZA FILHO, 2008; SÁ 2007; PRADO, 2007; LINHARES, 1999), mas como comunidades remanescentes de quilombos ou simplesmente quilombos.

\section{QUESTÕES ANALÍTICAS E IDENTITÁRIAS}

Com relação à utilização dos conceitos como forma de construir uma identidade a ser manejada no plano político "não é difícil concordar com o fato de que, do ponto de vista sociológico, toda e qualquer identidade é construída. A principal questão, na verdade, diz respeito a como, a partir de quê, por quem, e para quê isso acontece" (CASTELLS, 2001, p. 23).

Aqui caberia estabelecer uma distinção fundamental, já trabalhada por Paula Andrade (2003), e também referida às comunidades remanescentes de quilombo, aquela entre

[...] categorias analíticas, elaboradas como ferramentas teóricas para compreender essas realidades, e categorias nativas, aquelas adotadas pelos

Novos Cadernos NAEA • v. 16 n. 1 • p. 61-78• jun. 2013 
próprios camponeses para se autodefinir, para se diferenciar de outros, para enfrentar situações de conflito nas quais se vêem ameaçados, principalmente em seus direitos territoriais (PAULA ANDRADE, 2003, p. 37).

Entre as necessidades dos grupos e o reconhecimento oficial de direitos, que o texto constitucional, em seu artigo 68, dos Atos das Disposições Constitucionais Transitórias assegura, existe um campo de disputa, no qual os mediadores assumem um lugar de destaque. Funcionando como pontes entre o Estado e os grupos beneficiários, encetam ações que pretendem, por uma parte, assegurar um certo protagonismo do seu papel político e, por outra, conferir uma unificação de discursos em relação às identidades coletivas e diferenciadas, fundindo as reivindicações com os novos signos identitários que, do ponto de vista estratégico, poderiam promover a garantia de direitos territoriais.

Aqui reside um deslocamento, ou melhor, uma confusão em transformar conceitos em categorias nativas ou fatores de autodefinição. Esse movimento, ainda que privilegiando a garantia de direitos, tenta unificar artificialmente situações sociológicas diferenciadas em algo homogêneo, recoberto por designações genéricas como comunidades remanescentes de quilombos ou simplesmente quilombos. Os elementos identitários referentes às situações sociológicas que operam no interior dos grupos acabam sendo eclipsados por esse movimento militante, numa espécie de politização semântica.

A preocupação das instâncias de mediação ao falar nos termos do Estado, ou seja, adotando designações próprias do reconhecimento oficial, acaba funcionando como um tipo de violência que não é reconhecida como tal. A suposta positividade da adoção de tais designações faz com que as categorias nativas fiquem em segundo plano, já que não fazem parte do léxico estatal que a luta pelo reconhecimento define.

Categorias de autodefinição, como preto, por exemplo, referida a muitas situações sociológicas identificadas, como terras de preto, perdem a sua força de semântica social no momento da ação reivindicatória, já que no diálogo com o Estado não têm a mesma força simbólica e política que as de quilombola ou remanescente de quilombo, ainda que nos planos localizados sejam decisivas para a compreensão das especificidades sociais e históricas dessas unidades sociais. A terra de preto é "uma terra particularizada por fornecer ao grupo que dela usufrui mecanismos próprios de identificação” (GUSMÃO, 1995, p. 68).

A redefinição conceitual implica também numa adequação aos contextos políticos nos quais as pressões sociais ou o próprio Estado impõem determinados temas como problemas a serem examinados segundo os interesses em disputa. Como sugere Pierre Bourdieu (1994), 
[...] es pot comparar el camp a um joc (per a diferencia d'un joc, no és pas el product d'uma creació deliberada, ni obeeix a regles, o més ben dit, a regularitats que siguin explicites i codificades). Hi ha, per tant, envits que són, essencialment, el product de la competició entre els jugadors [...]. Els jugadors accepten les regles pel simple fet de jugar el joc, i no pas per un 'contract'; ho fan amb la convicció que val la pena jugar-hi, que el joc s'ho val" (BOURDIEU, 1994, p. 74).

No jogo político, que se reflete em diferentes campos - intelectual, institucional e de mediação - o Estado, ao mesmo tempo em que impõe o objeto de disputa, estrategicamente sugere que dá importância às demandas oriundas desses campos, fazendo com que os atores vinculados aos mesmos, joguem o jogo posto em funcionamento.

O sentido de jogo, nesse caso, assume uma conotação peculiar, pois se assemelha a disposições estratégicas dos agentes sociais e representantes de instituições que, reconhecendo a dinâmica do jogo, estabelecem seus próprios movimentos no ato de jogar, valendo-se do capital que dispõem para participar do jogo e a sua própria posição no campo em disputa.

O jogo posto em funcionamento configura-se como um campo de forças, no qual os que se colocam em disputa valem-se, inclusive, da dinâmica da disputa para assegurar a sua permanência no campo.

Imaginem-nos que cada jugador té devant seu unes piles de fitxes de diferents colors, que corresponen a les diferents espécies de capital de que disposa. Ara, la força relativa en el joc de cada jugador, la seva posició en l'espai de joc, i també les seves estratègies de joc, allò que es diu la seva “jugada”, els monviments que emprèn, més o menys arriscats, més o menys prudents, més o menys subversius o conservadors, depenen tant del volum global de les seves fitxes com de l'estructura de la pila de fitxes. És a dir, del volum global de l'estructura del seu capital (BOURDIEU, 1994, p. 75).

A politização semântica que mencionei anteriormente se justificaria por dois aspectos. O primeiro estaria relacionado com uma certa naturalização, por parte dos mediadores e instituições, da ideia de quilombo, quilombola ou remanescente de quilombo. É como se tais categorias, ao serem manejadas, fossem autoexplicativas, emprestando sentido e força política. O segundo estaria relacionado com os níveis de atribuição. Ainda que não se possa dividir mecânica e rigidamente tais competências, aos intelectuais caberia a tarefa de atuar no plano analítico e conceitual. Aos mediadores, a esfera da ação política e do diálogo com instâncias do Estado, assim como com agências de apoio e cooperação, tidas como parceiras nas lutas relacionadas com as chamadas comunidades remanescentes de quilombos.

Em relação a tal aspecto, e sem nenhuma conotação desqualificadora, na dinâmica do campo de disputa, a distribuição de competências não obedece a uma 
rigidez ortodoxa, já que se pode constatar, e guardando-se as devidas proporções, há intelectuais (no sentido acadêmico do termo) atuando como mediadores, e mediadores que procuram atuar como intelectuais, já que sua prática política requer a aplicação de conhecimento especializado.

Essa separação, ainda que problemática, mostra-se funcional, pois dilui nos diferentes campos parcelas de responsabilidades, que acabam sendo utilizadas para justificar a existência e permanência desses campos. A consolidação das noções de quilombo ou remanescentes de quilombo nos campos político ou intelectual faz com que seu uso e visibilidade adquiram uma força que transcenda o próprio contexto social de produção de significado, destinando-se a emprestar níveis de poder e prestígio, seja ele político ou acadêmico.

Essa tendência de divisão de atribuições, além da dimensão técnica, é determinada por um modelo de relação com o Estado - ou mesmo com instituições nacionais e internacionais - e orientado para a garantia de direitos ou para a luta contra formas de expropriação e violência. Esse modelo de relação acaba reforçando os papéis e dando visibilidade àqueles que tomam parte em cada um desses campos.

Ademais, sob esse aspecto, a divisão das atribuições contribui para que as noções de quilombo e remanescentes de quilombo, em alguns casos, transcendam as esferas situacionais, remetendo a um quadro mais amplo, já que pretendem cobrir situações análogas, das quais um dos traços característicos é a luta pela manutenção de territórios historicamente ocupados. Nesse movimento, parece existir um princípio de unidade que se fundamenta na descontinuidade, ou seja, nas realidades particulares que mobilizam seus integrantes para lutarem também as suas lutas, no sentido de verem atendidos seus pleitos específicos.

Ao mencionar anteriormente que certos conceitos e categorias são datados, não pretendi estabelecer a preocupação com a ideia de um marco zero conceitual. Quis apenas argumentar, no sentido de que o reconhecimento social de um problema, no caso o vivido pelas chamadas comunidades remanescentes de quilombos espalhadas por diferentes estados brasileiros, acaba gerando o reconhecimento social de determinados conceitos. Foi em função disso que me referi à ideia de descontinuidade conceitual, já que o seu grau de importância deriva, em grande parte, de seu reconhecimento em diferentes âmbitos e momentos políticos.

As diferentes situações sociológicas às quais os conceitos de quilombo ou remanescentes de quilombo se referem, contribuem para a emergência de tais conceitos somente no momento em que essas realidades localizadas, com suas especificidades sociais e históricas, são convertidas em problemas sociais. Segundo Lenoir, "O que é constituído como 'problemas sociais' varia segundo as épocas e as regiões e pode desaparecer como tal” (LENOIR, 1998, p. 63-64). 
A categoria quilombola, por exemplo, não é uma categoria de autodefinição, nos mesmos termos que preto e caboclo o são em outros contextos. Em outras palavras, é a partir do reconhecimento social do problema que tal categoria passa a ocupar um lugar de destaque em diferentes campos, seja ele intelectual, político ou institucional, já que se impôs socialmente como relevante, em função de sua vinculação direta com o problema social que lhe dá sustentação e visibilidade. Em função disso, a ação política, principalmente dos mediadores, tende a apresentá-la como fator de mobilização e identidade.

A necessidade de reconhecimento formal de territórios como um problema a ser superado requer uma certa visibilidade. Nesse sentido, "para que um 'problema' tome a forma de um problema social, não basta que encontre agentes socialmente reconhecidos como competentes para examinar sua natureza e propor soluções aceitáveis; ainda será preciso, de alguma forma, impô-lo no cenário dos debates públicos" (LENOIR, 1998, p. 88).

A visibilidade do problema, para que seja reconhecido socialmente como tal, requer a ação e mobilização dos agentes sociais para que suas demandas despertem interesses, a ponto de torná-las dignas de atenção. Em relação à legitimação do problema, ainda segundo o autor:

[...] esta não é necessariamente induzida pelos simples reconhecimento público do problema, mas pressupõe uma verdadeira operação de promoção para inseri-lo no campo das preocupações 'sociais' do momento. Em suma, a essas transformações objetivas, sem as quais o problema não seria levado em consideração, acrescenta-se um trabalho específico de enunciação e formulação públicas [...] o trabalho de formulação pública pode surgir da iniciativa dos atores do próprio campo político que, na constituição de um problema social, encontram uma causa de interesse geral a ser definida (LENOIR, 1998, p. 84).

Os problemas relacionados às comunidades remanescentes de quilombos, como formulações públicas, acabam criando condições para que o Estado se manifeste em relação aos mesmos, passando a inseri-los em sua agenda. Apesar desse reconhecimento público do Estado, em muitos casos entendido como uma dívida histórica para com os descendentes de escravos que constituíram situações sociológicas particulares, não significa que os problemas socialmente reconhecidos tenham fácil solução.

A prova disso é que se observa a vigência de uma ambiguidade referente à posição do Estado: do ponto de vista do discurso, reconhece a importância histórica e social dessas situações sociológicas; no plano político, impõe obstáculos que dificultam a garantia dos direitos que esse reconhecimento prevê. 
Uma estratégia adotada pelo Estado, que pretende reforçar a ideia de reconhecimento e o desejo de ver atendidas as demandas dos segmentos sociais, é a da adoção dos próprios termos cunhados pelos intelectuais e usados pelos agentes sociais e pelas instâncias de mediação com os quais estabelece interlocução. Nesse caso, caberia também saber o que está subjacente a essa posição do Estado como fonte de enunciação, ao adotar noções como quilombolas e remanescentes de quilombos.

Uma primeira observação em relação ao uso, por parte de setores do Estado, de conceitos como remanescentes de quilombos ou quilombolas formulados no campo intelectual é que, semelhante aos mediadores, operam com uma naturalização dos mesmos. O que diferencia essa naturalização operada por ambos são os fatores ou interesses em jogo no momento da publicização de tais noções a seus interlocutores.

Uma segunda observação em relação ao uso dessas noções, por parte do Estado, ao dialogar com os mediadores, enquanto porta-vozes dos segmentos que representam, é que o mesmo pode ser entendido como um ato de violência simbólica e de demonstração de poder. Ao fazer uso dessa linguagem étnica, o Estado dissimula sua dominação, já que "tot intercanvi lingüistic conté la virtualitat d'un acte de poder i més en la mesura que implica agents que ocupen posicions asimètriques en la distribuició del capital pertinent" (BOURDIEU, 1994, p.122).

Uma terceira observação com relação à adoção de tais noções pelo Estado é que se verifica a ocorrência do que Henri Lefvbre (1970, p. 24) denominou de rapto ideológico. A incorporação de tais termos pelo Estado, para estabelecer interlocução, seja com os agentes sociais, seja com mediadores ou intelectuais, representa "a tradução de uma noção segundo significações que são estranhas à sua extração original" (MARTINS, 1986, p. 22-23).

O rapto dessas noções por parte de instâncias do Estado, procura atender fundamentalmente a necessidades ideológicas e interesses políticos. Segundo Bourdieu:

[...] Fins i tot l'intercanvi lingüístic més simple posa em joc uma xarxa complexa i ramificada de relacions de força històriques entre el locutor, dotat d'autoritat social específica, i el seu interlocutor o el seu públic, que reconeix la seva autoritat em diferents graus" (BOURDIEU, 1994, p. 120).

A manobra adotada pelo Estado de falar nos mesmos termos de seus interlocutores, configura-se no que Bourdieu (1994, p. 121) denominou de estratégia da condescendência, já que “abidicant temporalment i d'una manera ostentatòria de la seva posició dominadora, fent veure que es posa al nivell del seu 
interlocutor, el dominador aprofita de totes maneras la seva relació de domini, que segueix existint, bo i negant-la".

O rapto ideológico dessas noções por parte do Estado, deixa entrever dois aspectos fundamentais. O primeiro é a distinção entre um conceito e um termo. A substância do conceito é esvaziada pelo uso oficial, transformando-o em um simples termo que serve apenas a seus propósitos discursivos, para dar a entender que fala a mesma linguagem de seus interlocutores. O segundo é a descoberta, por parte do Estado, do poder das palavras e o uso estratégico delas para atender aos seus objetivos. Apesar de usá-lo com outros propósitos, o Estado reconhece o significado social e político das noções de quilombo, quilombolas e remanescentes de quilombos. Reconhecendo a eficácia social desses termos, acabam sendo manipulados, de modo que seus interlocutores interpretem como sendo apropriados nos mesmos termos que estes. Isto "crea la crença en la legitimitat de las paraulas i de les persones que les pronuncien” (BOURDIEU, 1994, p.126).

\section{CONCLUSÃO}

Como tentei assinalar ao longo deste artigo, essa múltipla hermenêutica possui distintas fontes de enunciação, com fundamentos e interesses específicos. As emanações derivadas dos conceitos de quilombo ou remanescentes de quilombos permitem identificar uma arena não isenta de conflitos, que faz com que se instaure, para além de sua importância como instrumento que pode contribuir para a garantia de direitos territoriais a segmentos sociais diferenciados, um campo de disputa pelo poder de nomear, classificar, manipular e interferir.

\section{REFERÊNCIAS}

ALMEIDA, A. W. B. de. Os quilombos e as novas etnias. In: Quilombos: identidade étnica e territorialidade. Rio de Janeiro: ABA/FGV, 2002. p. 43-81.

ALMEIDA, A. W. B. de. Quilombos: sematologia face a novas identidades. In:

Frechal - Terra de preto. Quilombo reconhecido como reserva extrativista. São Luís: SMDDH/PVN, 1996. p. 1-19.

ALMEIDA, A. Wagner Berno de. Terras de preto, terras de santo, terras de índio uso comum e conflito. In: Terras de quilombo, terras indígenas, "babaçuais livres", "castanhais do povo", faxinais e fundos de pasto: terras tradicionalmente ocupadas. Manaus: PPGSCA-UFAM; Fundação Ford, 2006. p. 101-123.

Novos Cadernos NAEA • v. 16 n. $1 \bullet$ p. 61-78 • jun. 2013 
ARRUTI, J. M. Mocambo - antropologia e história do processo de formação quilombola. Bauru: EDUSC/ANPOCS, 2006.

BARTH, F. Introducción. In: Los grupos étnicos y sus fronteras. México: Fondo de Cultura Económica, 1976. p. 9-49.

BOURDIEU, P. Campo de poder y campo intelectual. Argentina: Folios Ediciones, 1983.

BOURDIEU, P. Economia das trocas lingüísticas. São Paulo: EDUSP, 1996.

BOURDIEU, P.; WACQUANT, L. J. D. Las finalitats de la sociologia reflexiva (el Seminari de Chicago). In: Per a una sociologia reflexiva. Barcelona: Herder, 1994. p. 45-187.

BOURDIEU, P. Economia das trocas simbólicas. São Paulo: Perspectiva, 1992.

BRASILEIRO, S.; SAMPAIO, J. A. Sacutiba e Riacho de Sacutiba: uma comunidade negra rural no oeste baiano. In: Quilombos: identidade étnica e territorialidade. Rio de Janeiro: ABA/FGV, 2002. p. 85-108.

CASTELLS, Manuel. Paraísos comunais: identidade e significado na sociedade em rede. In: O poder da identidade. São Paulo: Paz e Terra, p. 21-92, 2001.

DOMINGUES, J. M. Sociologia e modernidade. Rio de Janeiro: Civilização Brasileira, 1999.

FERNANDES, C. A. Remanejamento compulsório de segmentos camponeses: o caso do Centro de Lançamento de Alcântara. Relatório de Qualificação de Doutorado. São Paulo: FFLCH/USP, 1994.

FIGUEIREDO, A. V. O Caminho Quilombola - sociologia jurídica do reconhecimento étnico. Curitiba: Appris, 2011.

FOUCAULT, M. La arqueologia del saber. México; Madrid: Siglo XXI, 1997.

GEERTZ, C. Uma descrição densa: por uma teoria interpretativa da cultura. In: GEERTZ, C. A interpretação das culturas. Rio de Janeiro: Guanabara Koogan, 1989. p.13-41.

GIDDENS, A. As conseqüências da modernidade. São Paulo: Unesp, 1991.

GIDDENS, A. New rules of sociological method. London: Hutchinson, 1974.

GUSMÃO, N.M.M. de. Caminhos transversos: território e cidadania negra. In: Terra de Quilombos. Rio de Janeiro: ABA, 1995. p. E1-E10. 
LEFBVRE, H. Du rural à l'urban. Paris: Anthropos, 1970.

LEITE, I. B. Quilombos e quilombolas: cidadania ou folclorização. Horizontes Antropológicos, Porto Alegre, v. 5, n. 10, 1999.

LENOIR, R. Objeto sociológico e problema social. In: CHAMPAGNE, P. (Org.) Iniciação à prática sociológica. Petrópolis: Vozes, 1998. p. 59-105.

LINHARES, L. F. do R. Terra de preto, terra de santíssima. Da desagregação dos engenhos à formação do campesinato e suas novas frentes de luta. 1999. $193 \mathrm{f}$. Dissertação (Mestrado em Políticas Públicas) - Programa de Pós-graduação em Políticas Públicas, Universidade Federal do Maranhão, São Luís, 1999.

MARTINS, J. de S. As coisas no lugar: da ambigüidade à dualidade na reflexão sociológica sobre a relação cidade-campo. In: MARTINS, J. de S. Introdução crítica à sociologia rural. São Paulo: Hucitec, 1986. p. 11-38.

O’DWYER, E. C. Os quilombos e a prática profissional dos antropólogos. In: Quilombos: identidade étnica e territorialidade. Rio de Janeiro: ABA/FGV, 2002. p. 13-42.

O'DWYER, E. C. Remanescentes de quilombos na fronteira amazônica: a etnicidade como instrumento de luta. In: Terra de Quilombos. Rio de Janeiro: ABA, 1995. p $11-111$.

PAULA ANDRADE, M. de. De pretos, negros, quilombos e quilombolas: notas sobre a ação oficial junto a grupos classificados como remanescentes de quilombo. Boletim Rede Amazônia, Rio de Janeiro, v. 2, n. 1, p. 37-43, 2003.

PRADO, R. Todo Ano Tem - as festas na estrutura social camponesa. São Luís: EDUFMA, 2007.

SÁ, L. M. O Pão da Terra - propriedade comunal e campesinato livre na Baixada Ocidental maranhense. São Luís: EDUFMA, 2007.

SOUZA FILHO, B. Bom Sucesso: terra de preto, terra de santo, terra comum. São Luís: EDUFMA, 2008.

SOUZA FILHO, B.; PAULA ANDRADE, M.. Relatório antropológico de identificação da Comunidade Remanescente de Quilombo Santa Maria dos Pinheiro. São Luís: INCRA, 2007.

WOLF, E. Inventando a sociedade. In: FELDMAN-BIANCO, B.; RIBEIRO, G. L. (Orgs.). Antropologia e Poder. Brasília: EDUNB, 2003. p. 307-324.

Texto submetido à Revista em 03.08.2012 Aceito para publicação em 13.05.2013

Novos Cadernos NAEA • v. 16 n. 1 • p. 61-78 • jun. 2013 